\title{
Early Detection of Toxic Profenofos Pesticide Exposure in Farmers using Simple Chemicals
}

\author{
Eram Tunggul Pawenang ${ }^{1}$, Hartono $^{2}$, Isna Qadrijati $^{3}$, Pranoto $^{4}$ \\ \{eramtepe@mail.unnes.ac.id ${ }^{1}$, hartonofkuns@yahoo.co.uk ${ }^{2}$, isnaqadrijati@staff.uns.ac.id ${ }^{3}$ \}
}

Universitas Negeri Semarang, Semarang, Indonesia ${ }^{1}$

Universitas Sebelas Maret Surakarta, Surakarta, Indonesia ${ }^{2,3,4}$

\begin{abstract}
One type of pesticide used by chilli farmers is profenofos. Therefore, to protect the health of farmers, we need to find materials that can be used as a basis for detection of pesticide poisoning. The research purposes to find materials that can be used early detection exposure of profenofos poisoning. This research with Qualitative and Quantitative methods. Qualitative test results Rhodamin $6 \mathrm{G}$ shows a change in color from red to pink when reacting with profenophos. The quantitative test results obtained Rhodamin $6 \mathrm{G}$ shows the value of $\mathrm{R}=0.891$ and the significance level is 0.007 . These results indicate a strong relationship between profenophos and Rhodamin $6 \mathrm{G}$. Suggestions from this research to design an advanced early detection device so that it can be applied in the field
\end{abstract}

Keywords: early detection, profenofos, rhodamin $6 \mathrm{G}$

\section{Introduction}

Pestisida is a poisonous substance but is needed by farmers to protect plants from attack pests and weeds [1][2]. Climate change is currently contributing to the increase in the use of pesticides. One of the most widely used groups of pesticides is orghanopospat which has an environmentally friendly nature and is less sensitive in killing non-target organisms [3]. The number of pesticides registered in Indonesia in 2006 was 1,557 and increased in 2010 to 2,628 pesticides with $65 \%$ being organophosphate [4]. One type of organophosphate insecticide that is widely used by farmers by vegetable and chilli farmers is Profenofos [5].

Exposure to pesticides organophospat can cause major health problems in spraying farmers are both me and chronic. Acute health disorders can vaporize disorders of skin sensitivity, skin and eye irritation. While chronic disorders can include neurological disorders, tremors, prostate cancer, pancreas, uterine cancer [6] [7] [8] .Organophosphate insecticide acts as a competitive inhibitor that can inhibit the activity of the cholinesterase enzymes that accumulate in the central and peripheral nervous system. Acetylcholine (AchE) is sensitive to organophosphate or carbamate pesticides and used as a biomarker for pesticide exposure [9].The use of AchE can detect exposure to poisoning in the chronic phase while for precautionary measures it should be able to detect exposure to poisoning before entering the body [10]. 
Therefore there needs to be an effort to find materials that can be used to detect profenophos exposure that exceeds the threshold when used by farmers in the field.One of the studies conducted to detect exposure to pesticides before entering the body was carried out [11]. The study used SPCE — chondosan Conductometry-based Conductometry Biosensors showed results that optimum biosensor performance was obtained at $25 \mu \mathrm{L} \mathrm{OPH}$, pH 8.5, with sensitivity to diazinon, malation, chlorpyrifos and profenofos. The use of biosensors requires high costs, so we need another alternative to detect exposure to pesticide poisoning using simple chemicals.

Chemicals that can be used include Methylen Blue, Rhodamin B and Rhodamin 6 G. The material can be used as an alternative because of its ability to detect various fields of application. Rhodamin $6 \mathrm{G}$ is a chemically stable organic dye, often used as a tracker to allow it to find the direction of transport and the flow rate of water. Research conducted by [12] to detect malathion and dimethoate pesticides showed that when both pesticides were added Cerium (IV) sulfate 6 rhodamine dye and chromotrope obtained detection limits of pesticide concentrations of 0.1-3.6 ug / $\mathrm{ml}$ for chromotrope and 0.2-4.2 ug / $\mathrm{ml}$ rhodamine 6G.

Methylen blue itself has been applied as an indicator of oxygen gas leaking. The results of the study of [13] showed that the manufacture of oxygen indicators with methylene blue as an ingredient is effective because it has a high sensitivity to oxygen. This indicator has a long shelf life, is irreversible, does not require expensive costs, and can be applied properly as in the form of sachets.

Rhodamin B is a coloring agent that is often found misusing it for food, especially snacks. Rhodamin B, which is a coloring agent in the form of green or reddish purple crystalline powder, has no odor, and is easily dissolved in a bright red color solution fluorinated as a textile or clothing coloring agent. Rhodamin B has a bright pink color. Rhodamin B color is easily identified in a sample process using a reagent kit [14].

Based on the description above, the purpose of this study is to determine the potential of Methylen Blue, Rhodamin B and Rhodamin $6 \mathrm{G}$ in detecting profenophos.

\section{Methods}

\subsection{Preparation for making methylen blue solution, rhodamin B, rhodamin 6 G, profenofos}

A solution of Methylen Blue, Rhodamin B and Rhodamin 6 G 5 ppm was made with how to weigh each 1 gram of material is then dissolved into 1 liter of Aquades, equivalent to 1000 ppm. Each solution was diluted by taking $5 \mathrm{ml}$ of the solution and diluted to a volume of 1 liter to obtain a solution of Methylen Blue, Rhodamin B and Rhodamin 6 G 5 ppm.

Profenofos $5 \mathrm{ppm}$ solution is made with how to take $2 \mathrm{ml}$ of the technical profenofos solution 500,000 ppm and then diluted with aquadest to $1 \mathrm{lt}$, equivalent to $1000 \mathrm{ppm}$. the next step is to take $5 \mathrm{ml}$ of $1000 \mathrm{ppm}$ then diluted to a volume of 1 liter so that a $5 \mathrm{ppm}$ profenofos.

\section{Qualitative test}

The solution of Methylen Blue, Rhodamin $6 \mathrm{G}$ and Rhodamin B were taken $10 \mathrm{ml}$ each, then the color changes were observed visually before adding a solution of profenofos or after adding profenofos and repeated 9 times. 


\section{Quantitative test}

This test is done by varying each concentration of profenofos by taking the $1000 \mathrm{ppm}$ profenofos solution as much as $2.5 \mathrm{~mL}, 5 \mathrm{~mL}, 7.5 \mathrm{~mL}, 10 \mathrm{~mL}, 12.5 \mathrm{~mL}$ and dissolved with $1000 \mathrm{~mL}$ measuring flask to the boundary mark of the flask. Profenofos which have been made variations mixed with variations of these dyes each with a concentration of $5 \mathrm{ppm}$ as much as $10 \mathrm{ml}$. The concentration variations were measured by the UV-Vis Instrument.

\subsection{Data analysis}

1) Qualitative test was observed by the five senses to see the color change

2) Quantitative test was carried out by anova test and linear regression

\section{Results and discussions}

\subsection{Qualitative test}

Test observations of chemical variations on the ability to react with profenofos

Table 1. Effect of variations in chemicals to react with profenofos

\begin{tabular}{lccccccccccc}
\hline Pigment & \multicolumn{1}{c}{ Profenofos's test } & Information \\
\cline { 2 - 9 } & 1 & 2 & 3 & 4 & 5 & 6 & 7 & 8 & 9 & \\
\hline Methylene Blue & - & - & - & - & - & - & - & - & - & Does not change color \\
Rhodamin B & - & - & - & - & - & - & - & - & - & Does not change color \\
Rhodamin 6 G & + & + & + & + & + & + & + & + & + & Change color \\
\hline
\end{tabular}

Table 1 shows that the results of tests of 3 chemicals, when reacted with profenofos, only Rhodamine $6 \mathrm{G}$ gave a color change reaction. Similarly, when repeated 9 times the results remain the same, only Rhodamine $6 \mathrm{G}$ which gives a change from red to pink.

The result show that the material of Methylen Blue when reacted with profenofos has not changed before and after. These results are due to the absence of energy interactions between profenophos and methylen blue so that the color change between the two substances is not visible [15] Rhodamin B also show the same results as methylen blue there is no change in color both before and after reacting with profenophos.

Results of Rhodamin $6 \mathrm{G}$ before and after the added profenofos shown the color changes from red to pink. These results are in accordance with research by [13]. showing the results that when pesticides were added Cerium (IV) sulfate 6 rhodamine coloring and obtained changes that were initially red to pink. But Rhodamine $6 \mathrm{G}$ to react with Profenofos does not need Cerium (IV) Sulfate to change color. This can provide benefits because it will be more easily applied in the field without preparing other ingredients so that Rodhamine $6 \mathrm{G}$ reacts with Profenofos

Qualitative test is done with the five senses namely the eyes. Then it can be possible that small color changes (faint) are not clearly visible. To ensure it all, then the 3 materials were continued to the quantitative test to see the color density changes that occur using a UV Vis spectrophotometer. 


\subsection{Quantitative test}

Test the effect of profenofos density on the concentration level when mixed with methylen blue

Table 2. Anova test results from the density of profenofos concentration with methylen blue

\begin{tabular}{rcccc}
\hline $\begin{array}{c}\text { Profenofos } \\
\text { concentration }\end{array}$ & The mean & SD & $95 \%$ CI & $p$ value \\
\hline $2.5 \mathrm{ppm}$ & 0.24 & 0.02944 & $0.1932-0.2868$ & 0.064 \\
$5 \mathrm{ppm}$ & 0.25 & 0.01414 & $0.2275-0.2725$ & \\
$7.5 \mathrm{ppm}$ & 0.26 & 0.01826 & $0.2309-0.2891$ & \\
$10 \mathrm{ppm}$ & 0.28 & 0.01826 & $0,2509-0,3091$ & \\
$12.5 \mathrm{ppm}$ & 0.24 & 0.01633 & $0.2140-0.2660$ & \\
\hline
\end{tabular}

Based on Table 2 shows the highest average density value at a concentration of $10 \mathrm{ppm}$ at 0.28 and the lowest density at a concentration of $2.5 \mathrm{ppm}$ and $12.5 \mathrm{ppm}$ each at $0.24 \mathrm{ppm}$. Statistical results show the value of 0.064 with alpha 0.005 so that it can be concluded that there is no difference in density in various concentrations of profenophos reacted with Methyline Blue. These results are due to Methylen Blue and Profenofos not reacting chemically.

The parameter that is the benchmark is variation in the concentration of profenophos whatever the absorbance is relatively constant when mixed with Rhodamin B. relatively constant absorbance only from methylene blue. Absorbance is a measure of the large number of compounds that absorb Uv-Vis light [16]. This result strengthens the skinative test which gives the result that Methyline Blue does not provide a color change reaction so it cannot be used as an indicator material for detection of profenophosal pestisda poisoning.

Test the effect of profenofos concentration on density level when profenofos mixed with rhodamine B

Table 3. Anova test results from the density of profenofos concentration with rhodamine B

\begin{tabular}{rcccc}
\hline $\begin{array}{c}\text { Profenofos con- } \\
\text { centration }\end{array}$ & The mean & SD & $95 \%$ CI & $p$ value \\
\hline $2.5 \mathrm{ppm}$ & 0.32 & 0.00816 & $0.3070-0.3330$ & 0.547 \\
$5 \mathrm{ppm}$ & 0.33 & 0.00816 & $0.3170-0.3430$ & \\
$7.5 \mathrm{ppm}$ & 0.32 & 0.00816 & $0.3070-0.3330$ & \\
$10 \mathrm{ppm}$ & 0.30 & 0.02944 & $0.2532-0.3468$ & \\
$12.5 \mathrm{ppm}$ & 0.30 & 0.05888 & $0.2063-0.3937$ & \\
\hline
\end{tabular}

Based on Table 3 shows that the highest average density value at a concentration of 5 ppm is 0.33 and the lowest is at a concentration of $10 \mathrm{ppm}$ and $12.5 \mathrm{ppm}$, respectively 0.30 ppm. Statistical results show the value of 0.547 with alpha 0.005 so it can be concluded that there is no difference in density between the various concentrations of profenophos reacted with Rhodamin B. 
This result strengthens the qualitative test which gives the result that Rhodamine B does not provide a color change reaction so that it cannot be used as an indicator material for detection of profenophosal pestisda poisoning.

Test the effect of profenofos concentration on concentration level when profenofos was mixed with rhodamine $6 \mathrm{G}$

Table 4. Anova test results from the density of profenofos concentration were reacted with rhodamine 6 G

\begin{tabular}{rcccc}
\hline $\begin{array}{c}\text { Profenofos con- } \\
\text { centration }\end{array}$ & The mean & SD & $95 \%$ CI & $p$ value \\
\hline $2.5 \mathrm{ppm}$ & 0.25 & 0.02449 & 0.2110 & 0.007 \\
$5 \mathrm{ppm}$ & 0.28 & 0.04243 & 0.2125 & \\
$7.5 \mathrm{ppm}$ & 0.30 & 0.04082 & 0.2350 & \\
$10 \mathrm{ppm}$ & 0.35 & 0.04082 & 0.2850 & \\
$12.5 \mathrm{ppm}$ & 0.375 & 0.06455 & 0.2723 & \\
\hline
\end{tabular}

Based on Table 4 shows the highest average density value at a concentration of 12.5 ppm of 0.375 and the lowest concentration at a concentration of $2.5 \mathrm{ppm}$ of $0.25 \mathrm{ppm}$. Statistical results show the p value 0.007 with alpha 0.005 so it can be concluded that there is a difference in concentrations between the various concentrations of profenophos reacted with Methyline Blue. This result strengthens the qualitative test that Rhodamine G provides a color change reaction from red to pink when reacted with Profenofos. Based on the two tests, Rhodamine $6 \mathrm{G}$ can be used as an indicator material for detection of profenofos pestisda poisoning.

Furthermore, to ascertain the shape of the density relationship between the various concentrations of profenophos and Rhodamine $6 \mathrm{G}$, a multiple linear regression test was used and the results as in Chart 1 below.

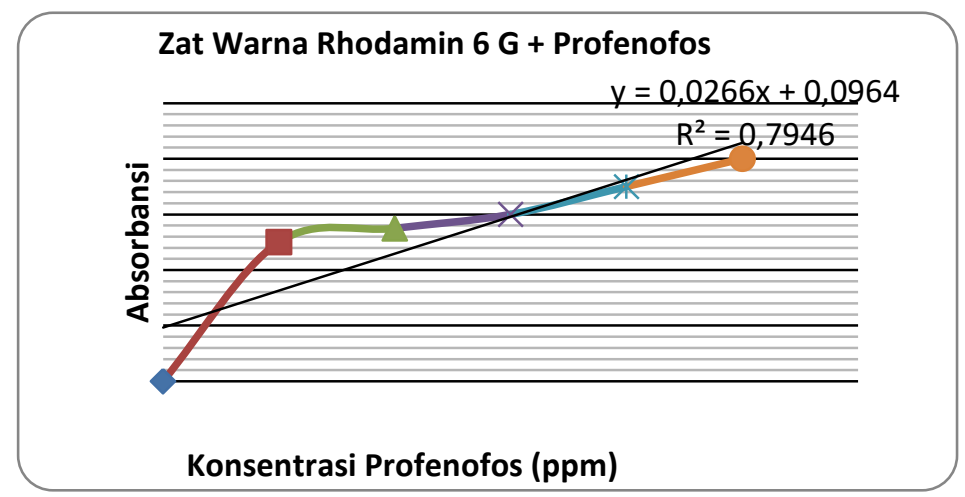

Fig. 1. Effect of Variation of Profenophos Concentration on density when Mixed Rhodamin 6 G

Chart 1 shows the density relationship between the various concentrations of profenophos and Rhodamine $6 \mathrm{G}$ in the direction it shows a linear form. Due to the number of 
repetitions that have not been so many then the line display does not look smooth. The results of the chart show that the greater the density of Profenofos, the higher the color density of Rhodamin 6 G. R Square (R2) gives a result of 0.7946 and $R=0.891$, this means that the model is very strong for the occurrence of color changes when profenophos is reacted with Rhodamine $6 \mathrm{G}$. The linear regression in chart 1 is influenced by the concentration and absorbance. Linear regression measurements satisfy the law of lamber beer where absorbance is directly proportional to concentration.

The stronger linearity $(\mathrm{R})$, the more valid the test is measured by the Uv-Vis Spectrophotometer [17]. The regression results of this study are not much different from the studies of cimetidine linearity obtained in the concentration range of 3-11 ppm. with the correlation coefficient on the Uv-Vis spectrophotometry method shows the results of the linear regression equation $y=0.04928 x+0.20908$ with a value of $r=0.99996$ [18].

The strength of the relationship model is needed to be able to make early detection of profenophosal poisoning exposure levels in the form of normal, moderate and dangerous. The current study is still a preliminary study because there is a need to follow up to make media or tools that are used as Rhodamine $6 \mathrm{G}$ material when used in agriculture. This is because the 6 $\mathrm{G}$ Rhodamine used is liquid so it spills easily. It also needs to be continued with the use of Rhodamine $6 \mathrm{G}$ which takes into account environmental factors in the field such as the temperature of the wind speed so that when reacting with Profenofos can run optimally.

\section{Conclusion}

Qualitative, quantitative and statistical test results show that chemicals that can be used as an indicator of early detection of Profenofos pesticide exposure are Rhodamine $6 \mathrm{G}$. The qualitative test results are shown by changing Rhodamine $6 \mathrm{G}$ from red to pink when in contact with porphenos, quantitative test results there is a difference in density (Absorbance) of the concentration of Profenofos reacted with Rhodamine B and has an $\mathrm{R}$ value of $0.891 \mathrm{p}$ value 0.007 . Because Rhodamine $6 \mathrm{G}$ is in liquid form, an early detection device needs to be designed that can be used as a material when applied in the field.

\section{References}

[1] WHO. Sound Management of Pestisicedes And Diagnosis And Treatment Of Pesticide Poisoning. .2006.

[2] Permentan, Minister of Agriculture Regulation No. 07 / Permentan / SR.140 / 2007 concerning Pesticide Registration Procedures and Procedures. 2007.

[3] Koleva, NG, Schneider, UA, The impact of climate change on the external costs of pesticide applications in US agriculture. 2009. International Journal of Agricultural Sustainability, 7 (3), 203216.

[4] Pohan, N. Pesticides and their Pollution. 2004. University of Northern Sumatra.

[5] Griffin, Jill. Customer Loyalty: 1996. How to Earn It, How to Keep It, New York: Simon and Chuster, Inc.

[6] Alavanja, MCR, Hoppin, JA, Kamel, F. Health Effects of Chronic Pesticide Exposure:2004. Cancer and Neurotoxicity. Annual Review of Public Health, 25, 155-197.

[7] Arcury, TA, Quandt, SA. Pesticides at work and at home: exposure of migrant farmworkers. 2003.. Journal of Medical Science, 362 (9400), 20-21.

[8] Rich Deborah, . Are pests the Problem or Pesticides. 2006. Biology Journal, 28 (1): 6-7. 
[9] Abhishek Srivastava. Post-stroke depression: Prevalence and relationship with disability in chronic stroke survivors, 2010. India

[10] Lionetto, MG, Caricato, R., Calisi, A., Giordano, ME, \& Schettino, T. Acetylcholinesterase as a Biomarker in Environmental and Occupational Medicine: New Insights and Future Perspectives. 2013. BioMed Research International, vol. 2013, issue 1, no. 8https://doi.org/10.1155/2013/321213

[11] NK Isvani, A. Mulyasuryani, S. Prasetyawan, 2015, Performance of Screened Carbon Electrode Condensometry (Screen Printed Carbon Electrode) SPCE - Chitosan for Detection of Diazinon, Malation, Chloririphos and Profenofos, 2015. Journal of Chemical Research and Development, Chemical Journal of VALENCY, vol 2015 , issue 1 (2), pp. 83-90. E-ISSN: 2548-3013, dx.doi.org/10.15408/jkv.v0i0.3156.

[12] Ayman A. Gouda, Alaa S. Amin, Ragaa, El Sheikh, Magda A. Akl, Sensitive Spectrophotometric Methods for Determination of Some Organophosphorus PestiCides in Vegetable Samples.. 2010. Chemical Industry \& Chemical Engineering Quarterly 16 (1) 11-18 (2010)

[13] Genuis, BSJ, Lane, K., Birkholz, D., Genuis, BSJ, Lane, K., \& Birkholz, D. Human Elimination of Organochlorine Pesticides: Blood, Urine, and Sweat (BUS) Study of Human Elimination of Organochlorine Pesticides: Blood, Urine, and Sweat (BUS) Study, 2016. vol. 2016, issue i, p. 128.https://doi.org/10.1007/s00244-010-9611-5

[14] Yuliarti, Nurheti. Awas Bahaya diBalik Lezatnya Makanan. 2007.. Yogyakarta: ANDI Yogyakarta

[15] Ge, X., Tao, Y., Zhang, A., Lin, Y., \& Du, D. Electrochemical Detection of Dual Exposure Biomarkers of Organophosphorus Agents Based on Reactivation of Inhibited Cholinesterase. 2013.. Analytical Chemistry, p. 1-23.https://doi.org/10.1021/ac402022p

[16] Dachriyanus..Spectroscopic Analysis of Structure of Organic Compounds.2014. Prints I. Padang: Andalas University Press. Thing. 39. MOH RI. (1980). Materia.

[17] Pecsok RL, Shields LD, Cairns T, McWilliam IG. . Modern Methods of Chemical Analysis. 2nd ed..1976. New York : John Wiley \& Sons, Inc.

[18] Naveed, S., Nawab, A., Farooq, N. Assay of cimetidine tablets and comparison of local and multinational brands using UV spectrophotometers. 2014. American Journal of Chemistry and Application, 1, (4). 